\title{
Tensile creep of miniaturized specimens
}

\author{
LiKang Luan and Heinz Riesch-Oppermann ${ }^{\text {a) }}$ \\ Karlsruhe Institute of Technology, Institute for Applied Materials (IAM), Eggenstein-Leopoldshafen D-76344, \\ Germany \\ Martin Heilmaier \\ Karlsruhe Institute of Technology, Institute for Applied Materials (IAM), Karlsruhe D-76131, Germany
}

(Received 15 May 2017; accepted 3 October 2017)

\begin{abstract}
A customized-built high-temperature tensile creep setup is introduced. Dog-bone shaped miniaturized specimens made from Nimonic-75 were tested as reference materials at temperatures of 850 and $1000{ }^{\circ} \mathrm{C}$ under constant load to verify the setup's accuracy. The results were compared to tensile creep tests with conventional (standard size) specimens at identical experimental conditions. The shape of the creep curves obtained in the miniaturized specimens exhibits a pronounced minimum creep rate, thus, being seemingly different from the ones obtained for the bulk samples which reveal a clear steady-state regime. This is partly due to the continuous increase of stress under constant load testing conditions and very likely affected by the much higher surface to volume ratio of the miniaturized specimens leading to the premature onset of tertiary creep. Still, a good agreement was obtained between the two specimen sizes with respect to the dependence of the steady-state (standard size) and minimum (miniaturized size) strain rate on applied stress at various temperatures leading to also comparable activation energies of the creep.
\end{abstract}

\section{INTRODUCTION}

The development of new materials applied in high temperature is a continual requirement, for example, the working temperature of a turbine blade is a key point for the power factor; therefore, the study of materials' creep properties is an essential precondition of various engineering applications at elevated temperatures.

With the development of microelectro-mechanical systems, mechanical testing of miniaturized specimens has become feasible to research the material's properties influenced by microstructure, size-effect, and extreme external conditions, etc. ${ }^{1,2}$ Several research groups have developed tensile test methods ${ }^{3,4}$ of materials on the microscale down to several $\mu \mathrm{m}$ even at a high temperature as well as methods for tensile creep testing., 5 With this article, a custom-built test $\operatorname{setup}^{7}$ for ceramic thin film micro-tensile testing is extended to the tensile creep testing of metallic specimens up to $1000{ }^{\circ} \mathrm{C}$. The purpose of this manuscript is 2-fold: it firstly introduces a customized high-temperature micro-tensile-creep setup for miniaturized specimens with the application of (i) digital image correlation (DIC) for the contactless strain measurement and (ii) a customized system for load and temperature control. Mechanical testing by

Contributing Editor: Mathias Göken

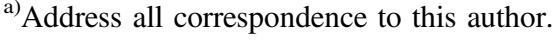

e-mail: heinz.riesch-oppermann@kit.edu

DOI: $10.1557 / j m r .2017 .414$ using miniaturized specimens is both economically and scientifically attractive for materials that are expensive and difficult to manufacture. The second purpose of this article is the discussion of variations in specimen size, the resulting accuracy and limitations with the designed test setup with respect to temperature, strain, and load control. From a scientific perspective, the advantage is that miniaturized specimens can be cut out from designated regions of the material so that heterogeneous local mechanical properties particularly present in multiphase materials, such as single crystalline Ni-base superalloys ${ }^{8}$ or directionally solidified eutectics, ${ }^{9}$ can be researched specifically.

In this manuscript, tensile creep tests with miniaturized specimens of the Nimonic-75 alloy, a single-phase $\mathrm{Ni}-\mathrm{Cr}$ solid solution as a simple reference material for high-temperature structural alloys, were carried out to verify the accuracy and potential of this setup. The results obtained will be assessed against tensile creep tests using conventional specimens under the same load and temperature conditions. ${ }^{10,11}$

\section{METHOD}

\section{A. Desgin and fabrication of the miniaturized specimens and the corresponding adapter}

A dog-bone shaped specimen is designed for the microtensile-creep tests. The specimens were cut by using electrical discharge machining (EDM) longitudinally from a Nimonic-75 cylinder with a $15 \mathrm{~mm}$ 
diameter. Nimonic-75 is a solid solution strengthened 80/20 nickel-chromium alloy with controlled addition of titanium and carbon, for which conventional creep results are readily available. ${ }^{11,12}$ The good mechanical properties, oxidation resistance at a high temperature, and the homogeneous microstructure, make Nimonic-75 an ideal reference material for the microtensile-creep setup at elevated temperatures. Figure 1 details the design of the creep specimen having a $1 \mathrm{~mm}$ gauge length of $0.2 \mathrm{~mm}$ width and $0.2 \mathrm{~mm}$ thickness. As the rectangular crosssectional area in this study is set as $0.04 \mathrm{~mm}^{2}$, the loads for the investigated stress ranging from 10 to $150 \mathrm{MPa}$ are $0.4-6 \mathrm{~N}$. The processing error of the EDM machine with respect to dimensional accuracy is $0.25 \mu \mathrm{m}$. Thus, the thickness and the width of each specimen were individually measured by an optical microscope (Nikon

AU1 Eclipse LV150N) before tensile creep tests to reduce the stress error caused by the dimensional uncertainty as well as by deviations from nominal dimensions due to polishing (mechanical polishing with 4000 grit sandpaper). The specimens were fixed in an adapter made by a high strength, precipitation, and dispersion-hardened nickel-base superalloy PM $3030^{12}$ to stabilize the specimens in the tensile creep tests. The design of the adapter and specimen mounting is displayed in detail in Fig. 1. As noted above, miniaturization should provide a means to specifically investigate small regions of inhomogeneities.
Therefore, the additional material necessary for the heads of the specimens which is needed for the stability of the specimens is not problematic in our case. This would of course be different, e.g., in the case of irradiated materials, where the overall dimensions of the specimens should be kept small. Then a new design of the grips would become mandatory.

\section{B. Micro-tensile creep setup}

The custom-built setup as shown in Fig. 2 has been originally designed by Leisen et al. ${ }^{7}$ for $\mathrm{SiC}$ thin-film high-temperature characterization and was adapted in the present manuscript for high-temperature microtensilecreep tests. The essential components of the setup in Fig. 2 are a vertical split hinged furnace for the specimen heating, a load cell combined with an actuator for load control, and a camera providing the DIC data for strain measurements. The optical access for the DIC measurement is provided via a fused silica glass rod with optically polished faces. The specimen is fixed in a vertical arrangement with two adapters and is placed in the center of the furnace. The temperature is measured with a thermocouple (type $S$ ) next to the specimen but without direct contact. To prevent oxidation, the furnace can be flooded by an inert gas such as Ar; however, all tests carried out in this study were done in air. (a)

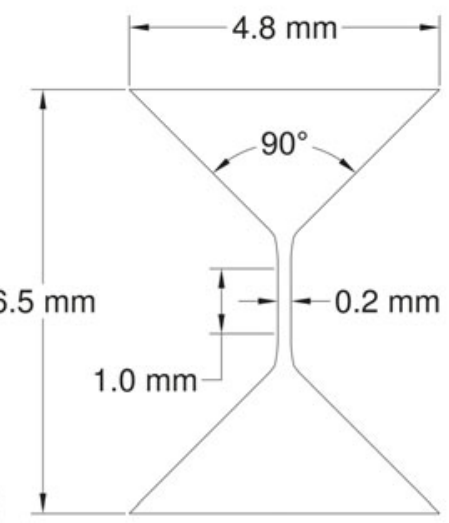

(b)

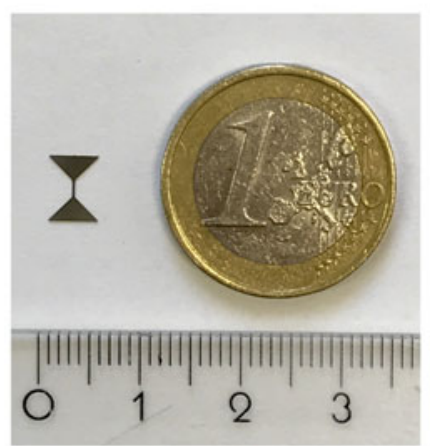

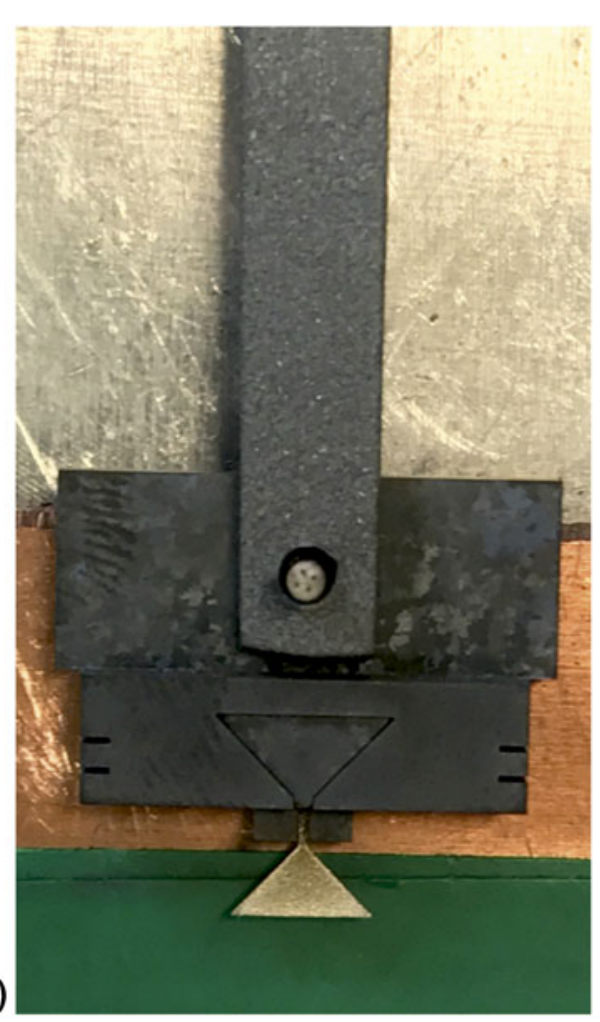

(c)

FIG. 1. Illustration of (a) the design drawing of the dog-bone shaped micro-tensile-creep specimens, (b) the appearance of the specimens after EDM manufacture, and (c) a mounted specimen in the adapter. (color online) 


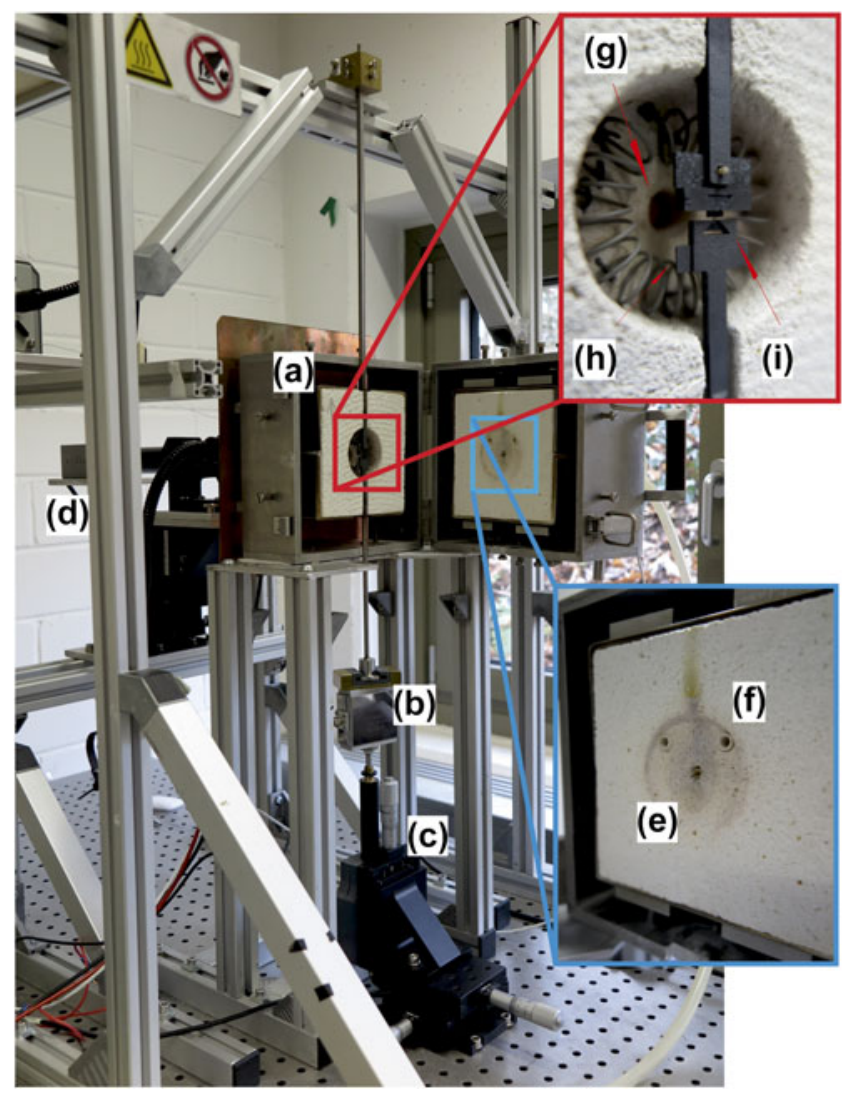

FIG. 2. Microtensile-creep setup. (a) Furnace, (b) load cell, (c) actuator, (d) camera for DIC analysis, (e) thermocouple through furnace door, (f) port for inert gas, (g) view port, (h) heating wire, and (i) the specimen and adapter after assembly. (color online)

Compared to the miniature tensile creep method in Ref. 4 that also uses DIC strain measurement but is limited to temperatures below $200{ }^{\circ} \mathrm{C}$, we obtain results up to $1000{ }^{\circ} \mathrm{C}$. A possible drawback of our current setup is the presence of ambient atmospheric conditions; however, since the tests are relatively short (less than $50 \mathrm{~h}$ ), oxidation at present seems not to be problematic. In Ref. 5, the gauge dimensions of the miniaturized specimens are $2 \times 3 \times 9 \mathrm{~mm}^{3}$, and the obtained creep behavior was obviously in a reasonable agreement with results from the standard specimens. Our specimens are roughly one order of magnitude smaller in each dimension $\left(0.2 \times 0.2 \times 1.0 \mathrm{~mm}^{3}\right)$, one aim of the paper being to extend size limits down to dimensions, where it might be practical to investigate the effect of specific microstructural features (orientation of plates in multiphase materials, grain boundaries, texture) on creep behavior.

\section{Heating method}

A resistance heating via a spiral-shaped Kanthal A1 wire with a thermocouple was used for temperature control. The thermocouple is set through the furnace door with its top point located next to the miniaturized specimen but without direct contact (see Fig. 3). The specimen is positioned in the center of the furnace at equal distance to the heating wire. A uniform temperature distribution in the furnace was confirmed by using measurements from three thermocouples at equal distance $(5 \mathrm{~mm})$ along the specimen. The maximum temperature difference between the upper/lower thermocouples and the central one is $\pm 2{ }^{\circ} \mathrm{C}$ at $1000{ }^{\circ} \mathrm{C}$. The temperature accuracy along the gauge length of the specimens is, therefore, expected to be better than $\pm 1{ }^{\circ} \mathrm{C}$. The heating system allows fast heating rates up to $30 \mathrm{~K} / \mathrm{s}$ with a temperature control stability of $\pm 0.1{ }^{\circ} \mathrm{C}$. Since the temperature fluctuation can cause thermal strain of the adapter and specimen as well as affect the load stability, it is important to maintain the temperature accurately. An unstable temperature control can also lead to the vibration of the specimen, resulting in a reduction in quality of the optical strain recording and a larger error in the DIC processing. A dwell time of at least one hour after heating is kept in order that the whole system reaches a stable condition.

\section{Specimen mounting}

The complete specimen installation before testing is shown in the red inlay of Fig. 2. The specimen and adapter are mounted using an auxiliary assembly construction. The dog-bone shaped specimen is first placed in the adapter and then fixed by a triangular cover. The adapter and the upper connect rod are assembled with a ceramic stick going through the openings in the upper rod and adapter to stabilize the specimen in a vertical direction under load (see Fig. 1). The assembled test structure is then transferred to the load system, and the specimen is positioned in the center of the furnace. The lower rod with a concave mouth holds the lower triangular part of the specimen and connects it to the load cell. Contact of the lower rod with the furnace is avoided to prevent any disturbing load influences.

\section{E. Strain measurement}

A contactless optical strain measurement using the DIC method is performed. A Matlab open source code with sub-pixel resolution is available for that purpose. ${ }^{13}$ The DIC method tracks the speckle patterns in images taken by optical microscopy and calculates the deformation of the region of interest by a cross correlation algorithm. ${ }^{14,15}$ Speckle patterns with good contrast are the necessary prerequisites for accurate strain measurements. ${ }^{16,17}$ In our case, the surface of the Nimonic-75 specimens provides sufficient contrast and random speckle patterns so that the DIC calculation is possible without additional surface treatment. A representative micrograph for the DIC calculation is displayed in Fig. 3, 


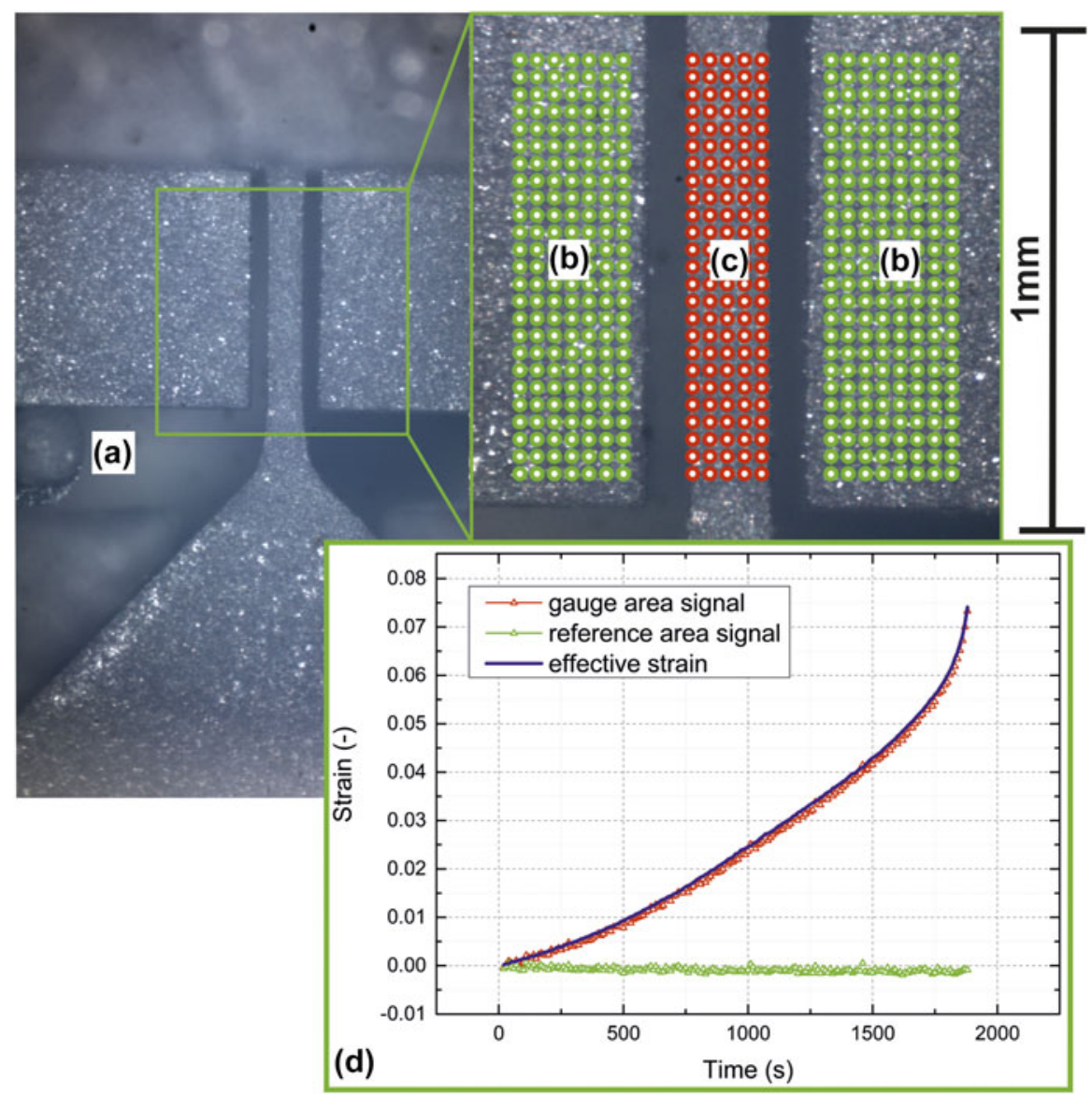

FIG. 3. A representative micrograph for DIC calculation. (a) The top point of thermocouple, (b) green dots show the undeformed reference area of the adapter in the experiments, (c) red dots represent the strained area along the gauge length of the specimen, and (d) the specimen strain is calculated by the difference in strain between these two areas. (color online)

showing the reference areas and the strained area used for the DIC method.

The area with green dots represents the reference area, an unstrained adapter surface that should undergo no deformation at constant temperature during the experiments. The area with red dots is the strained area along the gauge length of the specimen. By taking the signal from the two separate areas, two main sources of error in the optical strain recording can be eliminated: the out of plane shift and the rotation of the adapter and specimen. The detailed calculation of the strain errors caused by these two sources follows an analysis of Sutton et al. ${ }^{18}$ The strain error caused by an out of plane shift can be corrected by identifying the differential strain between the two areas because the adapter and specimen stay in the same translational plane in the experiments, resulting in the identical strain errors. The strain error caused by rotation is eliminated by seeking the central rotation point of both the areas and correcting the measured strains for artificial contributions from the specimen rotation. Additionally, the signal from the two different areas allows for corrections of irregular variations from optical disturbances as well as from drift of the whole arrangement leading to a sensitivity of strain measurements well below the noise level of the disturbances.

\section{F. Load and displacement control}

The microtensile-creep tests with this setup are performed under load control. A $10 \mathrm{~N}$ load cell (FN 3148A1-10 N from disynet, Brüggen-Bracht, Germany) and a DC actuator (M-230.25 from Physik Instrumente PI, Karlsruhe, Germany) are combined together to maintain a constant load in the tensile creep tests. The actuator has a $25 \mathrm{~mm}$ working distance and a minimum design resolution below $5 \mathrm{~nm}$. The accuracy of the load cell as specified by the manufacturer is $10 \mathrm{mN}$. Fluctuations in the load signal during high-temperature creep tests can be caused by the thermal expansion, by creep deformation of the loading rods as well as by the heating instability from the furnace. The corresponding fluctuation was measured to be $< \pm 1 \mathrm{mN}$ at room temperature and $< \pm 3 \mathrm{mN}$ at $1000{ }^{\circ} \mathrm{C}$. Apart from the load condition, the applied stress level is affected by variations in the size of the 
specimen's cross section, leading to an increasing stress error for smaller loads and cross sections because the relative uncertainties of the dimensional measurements and load fluctuations are increased. The maximum noise level in the stress signal is under $2 \%$. A detailed error analysis will be given in the following Sec. IV.

\section{RESULTS}

The accuracy and potential of this microtensile-creep setup were tested with specimens of Nimonic-75 at different temperatures and stresses in air, where results from the tensile creep tests with conventional specimens (diameter $6 \mathrm{~mm}$, gauge length $30 \mathrm{~mm}$ ) at the same load and temperature conditions are available. ${ }^{11}$ A representative diagram of tensile creep strain versus time at $1000{ }^{\circ} \mathrm{C}$ and $40 \mathrm{MPa}$ from a miniaturized specimen is shown in Fig. 3(d).

The DIC method calculates the strains in the gauge area (red curve) and reference area (green curve). As can be seen in Fig. 3(d), the green curve of the undeformed reference area reveals strain values around the zero point with some noise, proving thermal and measurement fluctuations to be on a negligible level. Likewise, the noise of the red curve displaying the elongation of the creep sample is on a similar level. Therefore, the (real) creep strain (blue curve) can be calculated as the differential value between these two strain curves, resulting in an improvement of the strain measurement accuracy. All the creep curves measured for the miniaturized $200 \times 200 \mu^{2}$ specimens possessed a smaller total strain $(\varepsilon \leq 0.15)$ compared to the conventional specimens $(\varepsilon \geq 0.3)$.

While the conventional specimens show a pronounced steady-state creep range, this is not normally the case for the miniaturized specimens. For those, rather a minimum creep rate, respectively, was observed in the strain rate versus the strain diagram as shown in Fig. 4(b) since identification of primary, secondary, and tertiary creep regions from strain versus time curves proved difficult. The minimum creep rates of the miniaturized specimens in this study and the steady-state creep rates of the conventional specimens ${ }^{11}$ are jointly plotted as the Norton plot in Fig. 5(a) for temperatures of $850{ }^{\circ} \mathrm{C}$ and $1000{ }^{\circ} \mathrm{C}$, respectively, and stresses in the range of 10 $150 \mathrm{MPa}$. Figure 5(a) clearly demonstrates that the minimum strain rates of the miniaturized specimens with stress from 20 to $70 \mathrm{MPa}$ at $850{ }^{\circ} \mathrm{C}$ (Norton creep exponent $n \approx 2.1$ ) fall into the same range as the values of the conventional specimens $(n \approx 2.8)$, especially when their scatter is taken into account. For stresses above $70 \mathrm{MPa}$, minimum creep strain rates from miniaturized specimens $(n \approx 7.4)$ tend to lie slightly above the steadystate creep strain rates for the conventional-sized samples $(n \approx 5.0)$. For $1000{ }^{\circ} \mathrm{C}$, results for conventional $(n \approx 3.5)$ and miniaturized $(n \approx 3.8)$ specimens agree very well over the entire range of stresses (10-80 MPa).

Additional tests with temperatures 900 and $950{ }^{\circ} \mathrm{C}$, under an initial stress of $30 \mathrm{MPa}$ were done to calculate the activation energy of the creep for the miniaturized specimens. Hence, data at an initial stress level of $30 \mathrm{MPa}$ for four temperatures of $850,900,950$, and $1000{ }^{\circ} \mathrm{C}$, respectively, were used in Fig. 5(b) showing the corresponding Arrhenius plot, from which an activation energy of $304 \mathrm{~kJ} / \mathrm{mol}$ was obtained, in good agreement with the results for conventional specimens of $285 \mathrm{~kJ} / \mathrm{mol}$ as well as for activation energies for self-diffusion and $\mathrm{Cr}$ diffusion according to Frost and Ashby. ${ }^{19}$

Some of the miniaturized specimens before and after tensile creep tests were mechanically polished to study the development of creep cracks. Figure 6 shows one etched surface of Nimonic-75 before testing and three fractured specimens at $850{ }^{\circ} \mathrm{C}$ under initial stress of 45,60 , and $80 \mathrm{MPa}$, respectively, and one specimen under an initial stress of $80 \mathrm{MPa}$ polished before fracture. From the left etched sample, an average grain diameter of $70 \mu \mathrm{m}$ can be extracted, i.e., compared to the cross section of the miniaturized specimens $200 \times 200 \mu^{2}$, approximately 2-4 grains exist along the cross section. Since the experiments were done with a single lot of material, the influence of the grain size could not be assessed. However, an influence of the small number of grains within the cross section on the minimum (steady state) creep rate could not be detected. The scatter in both, creep rate and lifetime is comparable to the results from conventional specimens, as can be seen from four results of tests at nominally equal conditions of $850{ }^{\circ} \mathrm{C}$ and $80 \mathrm{MPa}$, see Table I and Fig. 5 . Of the four replicated tests at $850{ }^{\circ} \mathrm{C}, 80 \mathrm{MPa}$ two specimens were used in the EDM condition (nonpolished), while two were mechanically polished with 4000 grit sandpaper on all four surfaces to remove the recast layer of about $4 \mu \mathrm{m}$. As shown in Fig. 5 we found no significant difference for the minimum creep strain rate from polishing. The fracture time has a range from 0.5 to $3 \mathrm{~h}$ with no obvious tendency from polishing. Obviously, the crack length density in the fractured specimens is larger at a lower stress; compare the three middle micrographs in Fig. 6 from right to left. Most cracks were observed to be generated from the surfaces with crack propagation along the grain boundaries, even though the specimens were mechanically polished with a 4000 grit paper before testing. One specimen was polished before fracture at $80 \mathrm{MPa}$ to study the crack growth process. For the interrupted test, an inhomogeneous crack distribution was observed; one region in the gauge length of the miniaturized specimen has a higher crack length density compared to the rest, where only small cracks generated from the surface were found. Two massive cracks from the opposite surface show the trend to join, indicating the potential location of the final fracture. 


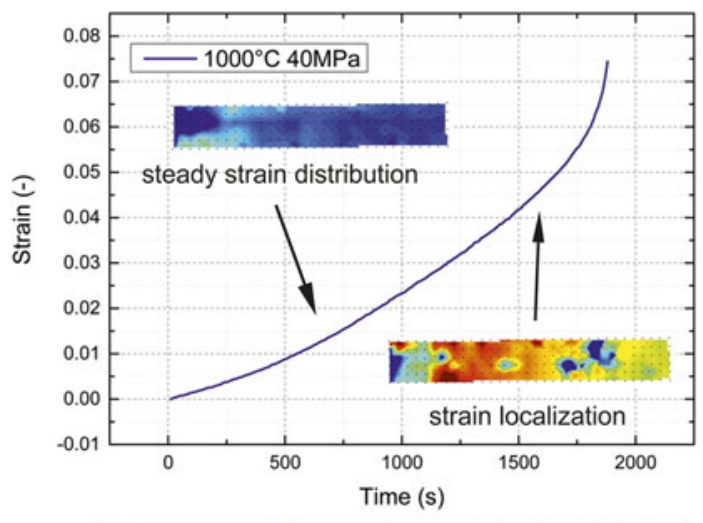

(a)
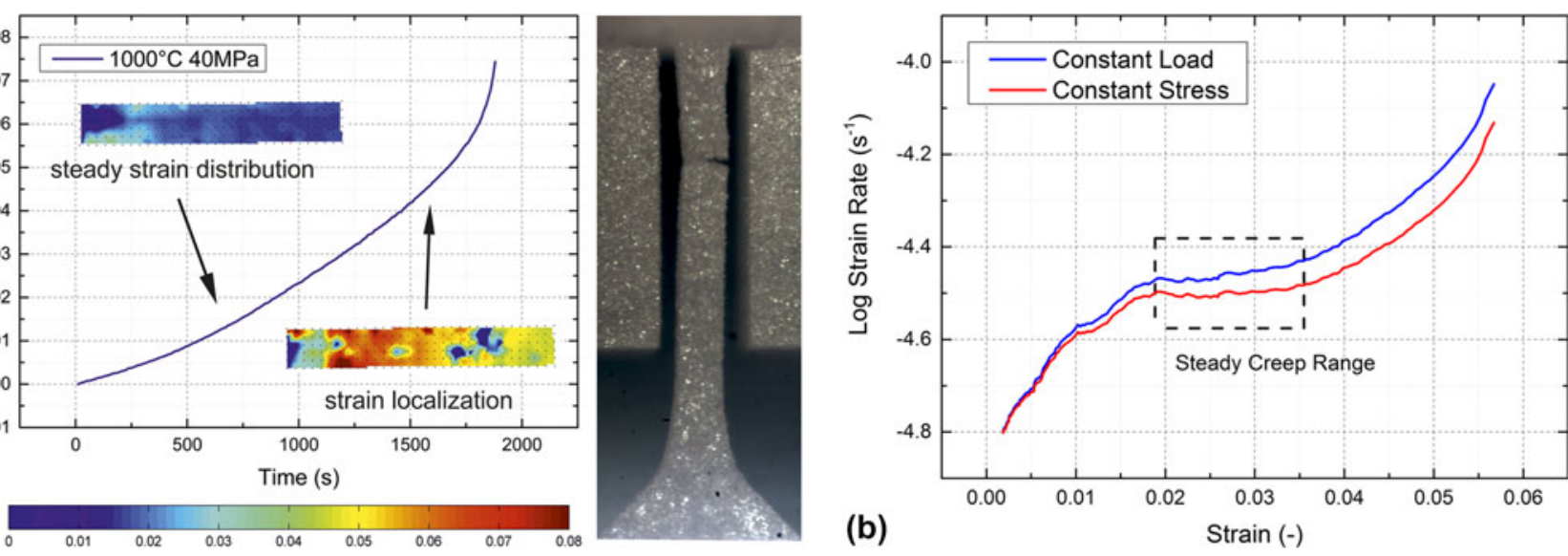

FIG. 4. (a) Strain distribution of a miniaturized specimen in the tensile creep test at $1000{ }^{\circ} \mathrm{C}$ and $40 \mathrm{MPa}$ by using DIC method. The color bar provides the strain legend. The strain localization leads to the stress concentration in the specimen and causes an accelerated tertiary creep stage. The fracture occurs at the position of strain localization. (b) Logarithmic plot of the creep rate versus strain comparing creep curves $\left(1000{ }^{\circ} \mathrm{C}\right.$ and $40 \mathrm{MPa}$ ) under constant load (measured) and constant true stress [calculated with converted creep rate according to Eq. (3) using a stress exponent $n=3.5$ according to Fig. 5(a)]. (color online)
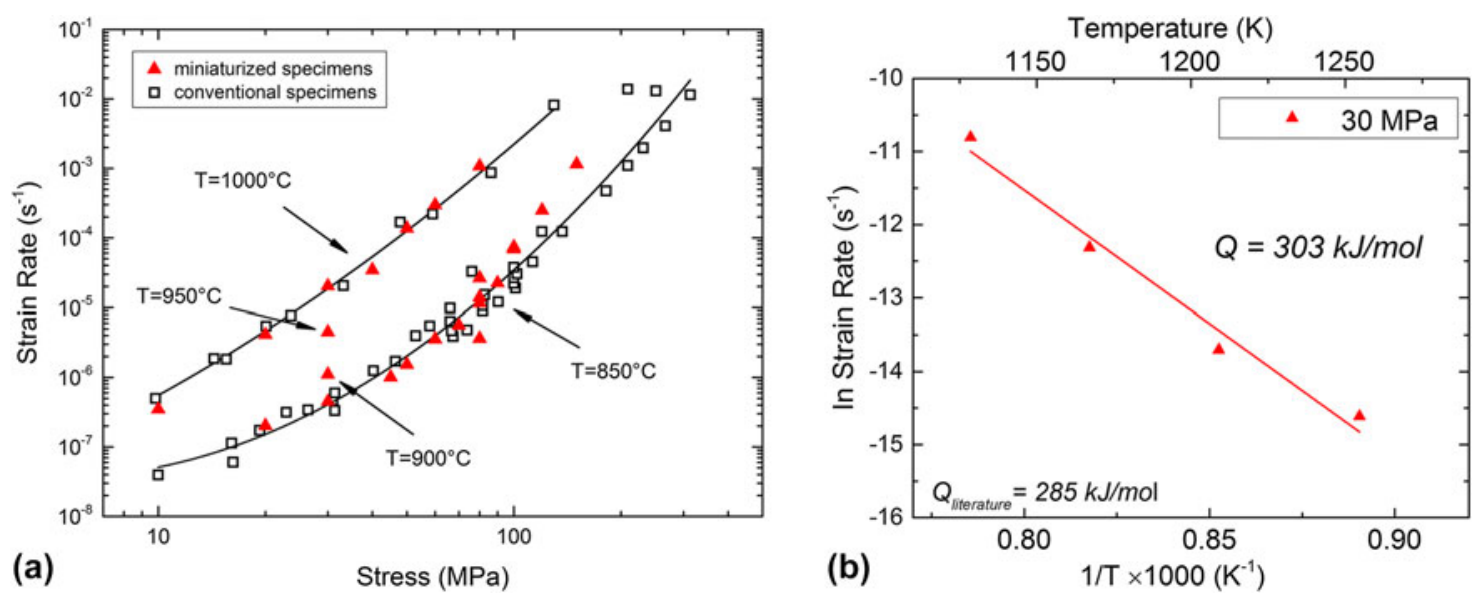

FIG. 5. (a) Norton-plot of Nimonic-75 summarizing minimum creep strain rates at 850 and $1000{ }^{\circ} \mathrm{C}$ with comparison of steady-state creep strain rates for conventional specimens from the literature. (b) Arrhenius plot for an initial stress level of $30 \mathrm{MPa}$ for four temperatures of 850, 900, 950, and $1000{ }^{\circ} \mathrm{C}$, respectively. (color online)

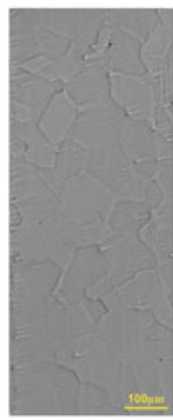

etched surface before tests

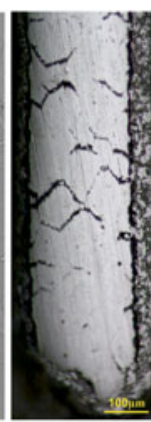

$45 \mathrm{MPa}$

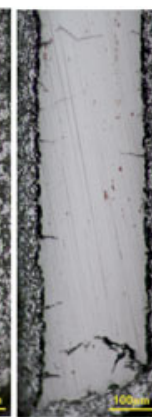

$60 \mathrm{MPa}$
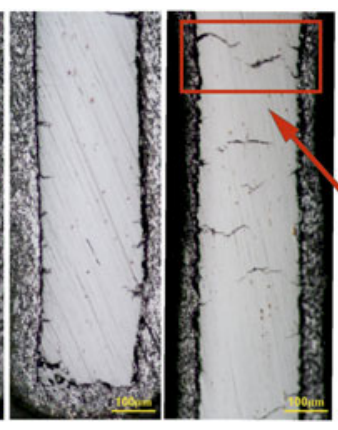

$80 \mathrm{MPa}$ before fracture
FIG. 6. Micrographs revealing the grain size and the crack status of the miniaturized specimens after tensile creep tests by $850{ }^{\circ} \mathrm{C}$ for stresses of 45, 60, and $80 \mathrm{MPa}$. The arrow shows where two massive cracks will probably lead to final rupture. (color online)

\section{DISCUSSION}

Tensile creep tests with miniaturized specimens of Nimonic- 75 by using the customized setup show reliable and reproducible results. The activation energy of $304 \mathrm{~kJ} /$ $\mathrm{mol}$ is in good agreement with the result of conventional specimens of $285 \mathrm{~kJ} / \mathrm{mol}$. In the Norton plot, Fig. 5(a), the minimum creep rates are in the same range as the steady-state creep rates for the conventional specimens. Still the following peculiarities were observed in tensile creep tests with the miniaturized specimens which need further discussion: the minimum creep rates tend to be slightly larger than those for the conventional specimens for stresses above $60 \mathrm{MPa}$. The fracture strain, which is above 0.3 for the conventional specimens, is significantly smaller for the miniaturized specimens and is generally 
TABLE I. Tensile creep results of Nimonic-75 for different specimen geometries at $850{ }^{\circ} \mathrm{C}$.

\begin{tabular}{|c|c|c|c|c|}
\hline Testing conditions & Gauge section & Minimum creep rate $\left(\mathrm{s}^{-1}\right)$ & Fracture strain $(\ldots)$ & Creep life time (h) \\
\hline $80 \mathrm{MPa}$; constant load unpolished & $\begin{array}{l}\text { Nominal: } 200 \times 200 \mu \mathrm{m}^{2} \\
\text { Actual: } 196 \times 195 \mu \mathrm{m}^{2}\end{array}$ & $2.48 \times 10^{-5}$ & 0.15 & 1.24 \\
\hline $80 \mathrm{MPa}$; constant load unpolished & $\begin{array}{l}\text { Nominal: } 200 \times 200 \mu \mathrm{m}^{2} \\
\text { Actual: } 197 \times 397 \mu \mathrm{m}^{2}\end{array}$ & $2.64 \times 10^{-5}$ & 0.26 & 1.18 \\
\hline $80 \mathrm{MPa}$; constant load polished & $\begin{array}{l}\text { Nominal: } 200 \times 200 \mu \mathrm{m}^{2} \\
\text { Actual: } 185 \times 183 \mu \mathrm{m}^{2}\end{array}$ & $1.02 \times 10^{-5}$ & 0.08 & 0.86 \\
\hline $80 \mathrm{MPa}$; constant load polished & $\begin{array}{l}\text { Nominal: } 200 \times 400 \mu^{2} \\
\text { Actual: } 182 \times 388 \mu \mathrm{m}^{2}\end{array}$ & $3.27 \times 10^{-5}$ & 0.28 & 0.97 \\
\hline 81.7 MPa; constant stress ${ }^{11}$ & Diameter $6 \mathrm{~mm}$ & $1.50 \times 10^{-5}$ & 0.41 & 5.45 \\
\hline $66 \mathrm{MPa}$; constant load polished & $\begin{array}{l}\text { Nominal: } 200 \times 200 \mu \mathrm{m}^{2} \\
\text { Actual: } 187 \times 184 \mu \mathrm{m}^{2}\end{array}$ & $3.83 \times 10^{-6}$ & 0.12 & 1.48 \\
\hline $66 \mathrm{MPa}$; constant load polished & $\begin{array}{l}\text { Nominal: } 200 \times 400 \mu^{2} \\
\text { Actual: } 186 \times 385 \mu \mathrm{m}^{2}\end{array}$ & $6.88 \times 10^{-6}$ & 0.21 & 2.18 \\
\hline $66 \mathrm{MPa}$; constant stress ${ }^{11}$ polished & Diameter $6 \mathrm{~mm}$ & $6.10 \times 10^{-6}$ & 0.40 & $\ldots$ \\
\hline
\end{tabular}

below 0.15 . Also the secondary, i.e., steady state, creep range is not well pronounced, rather a minimum creep rate is noted. In the following, an analysis of the accuracy of the customized setup will be given, and the observed results will be discussed.

\section{A. Accuracy of the customized setup}

The micro tensile creep tests were performed under constant load which means that an accurate calculation of the initial stress is essential. The error sources of the stress calculation basically stem from two aspects: the error measurement of the specimens' cross section and the fluctuation of load during experiments. The cross section of each specimen was measured with a Nikon Eclipse LV150N optical microscope, and the measurement error caused by the measuring uncertainty and the surface roughness is $\pm 1 \mu \mathrm{m}$. The measured fluctuation of load has a maximum amplitude of $3 \mathrm{mN}$ and is dependent on the load magnitude as well as on the test temperature. The corresponding error $\Delta \sigma$ in the stress $\sigma=F /(w \cdot t)$ from a Gaussian error analysis can be expressed by:

$$
\Delta \sigma=\sqrt{\left(\frac{\Delta F}{w \cdot t}\right)^{2}+\left(\frac{F \cdot \Delta t}{w \cdot t^{2}}\right)^{2}+\left(\frac{F \cdot \Delta w}{w^{2} \cdot t}\right)^{2}}
$$

here $F$ is load, $w$ and $t$ are the specimen's width and thickness, $\Delta w$ and $\Delta t$ are the dimensional measurement errors, and $\Delta F$ is the sum of the maximum fluctuation of the load amplitude $(3 \mathrm{mN})$ plus the maximum accuracy of the load cell $(10 \mathrm{mN})$ so that $\Delta F= \pm 13 \mathrm{mN}$. The nominal cross section of the miniaturized specimens is $200 \times$ $200 \mu^{2}$. At a stress of $25 \mathrm{MPa}$, corresponding to the load $1 \mathrm{~N}$, the relative stress error $\Delta \sigma / \sigma$ is $1.5 \%$. The stress error decreases with increasing stress: for initial stresses larger than $75 \mathrm{MPa}$, the relative error is below $0.8 \%$.

With the DIC method, displacements and strains are calculated from differences of gray values in digital images of the specimen's surface. The images are taken during the test and processed after the test is finished. The accuracy is determined by the resolution of the images and is enhanced by image processing methods that achieve subpixel resolution. ${ }^{14}$ The DIC code used for this study has a theoretical accuracy of 0.001 pixel, and the working accuracy according to the image quality is determined as \pm 0.02 pixel at room temperature. The corresponding strain accuracy in the region of interest in the miniaturized specimen containing 1000 pixels, thus, is $2 \times 10^{-5}$. For higher temperatures, optical disturbances reduce the accuracy of the system; still, at a temperature of $1000{ }^{\circ} \mathrm{C}$, the accuracy of strain measurement with the DIC method in this study is below $1 \times 10^{-4}$. The resolution limit for the strain rate is of the order of $10^{-8}\left(\mathrm{~s}^{-1}\right)$, and a minimum measurement time of $10^{4} \mathrm{~s}$ is required to achieve reliable data points, which is acceptable in comparison with the whole experimental period for this strain rate.

\section{B. Creep properties of the miniaturized specimens}

For a detailed understanding of the creep behavior of the miniaturized specimens, an analysis with the DIC method providing the strain distribution on the surface of the miniaturized specimen at $1000{ }^{\circ} \mathrm{C}$ and $40 \mathrm{MPa}$ is presented in Fig. 4(a).

A secondary creep range from strain 0.018 to 0.035 was determined with the analysis of strain distribution with the DIC method, Fig. 4(a) shows a homogeneous strain distribution within this stage. As the test proceeded, strain localization took place relatively early in the creep life of the specimen and kept increasing until fracture. Consequently, the creep rate increased as well and the appearance of steady-state creep in all the miniaturized specimens in this study was found to be much shorter, normally ranging from strain 0.02 to 0.05 , compared with the conventional specimens (typical strain range of 
secondary creep from 0.1 to 0.2 ). From the strain at 0.05 , all the creep curves have an accelerated creep rate (onset of tertiary creep). One reason for an early onset of tertiary creep may come from the fact that tensile creep tests in this study were carried out under a constant load which means that the true stress increased according to (assuming constant volume of the miniaturized specimens before tertiary creep):

$$
\dot{\varepsilon}=K \cdot \sigma_{\text {true }}^{n}=K \cdot \sigma_{0}^{n} \cdot(1+\varepsilon)^{n},
$$

here $K$ is a material constant depending on temperature and $n$ is the stress exponent of the Norton creep law [see Fig. 5(a)]. In Eq. (2), the effect of the specimen deformation on the effective stress in the gauge section was taken into account since it leads to a first-order correction, while discrimination of engineering and true strains is only second order and was not deemed necessary because of the rather small strain values of the miniaturized specimens. At $1000{ }^{\circ} \mathrm{C}$, the value of $n$ is around 3.5. A, and the corrected ("under constant true stress") strain rate $\left(\dot{\varepsilon}^{\prime}\right)$ can be obtained by:

$$
\dot{\varepsilon}^{\prime}=\frac{\dot{\varepsilon}}{(1+\varepsilon)^{n}}=K \cdot \sigma_{0}^{n}
$$

A correction for the effect of the specimen deformation on the stress is presented in Fig. 4(b). While the effect is clearly visible for the $40 \mathrm{MPa}$ test at $1000{ }^{\circ} \mathrm{C}$ [Fig. 4(b)], it is even more pronounced at higher stresses and lower temperatures. While the plateau and the transient to tertiary creep may be recognized in the first case, there is still a slight (albeit small-10\%) increase in the strain rate during a creep phase that might be considered as the secondary creep in the second case. The difference of creep rate at $1000{ }^{\circ} \mathrm{C}$ and $40 \mathrm{MPa}$ is small because the total strain here is only 0.06. Considering tests with higher stress $(80 \mathrm{MPa})$ and larger total creep strain as conventional specimens $(\geq 0.2)$, the increment of the stress should not be ignored. Strain localization was also observed at strain $\geq 0.035$, which causes an early fracture. To test samples at constant true stress in the future, one possible way would be to develop an in situ closed-loop strain-load control system.

Another issue which was claimed responsible for accelerated tertiary creep is specimen oxidation. ${ }^{20,21}$ Oxidation layers were also observed after the fracture of the Nimonic-75 miniaturized specimens at temperatures of 850 and $1000{ }^{\circ} \mathrm{C}$. The corresponding compact oxidation layers were $1.3 \mu \mathrm{m}$ at $850{ }^{\circ} \mathrm{C}$ and $2 \mu \mathrm{m}$ at $1000{ }^{\circ} \mathrm{C}$, resulting in a maximum stress error below $2 \%$. The experimental error caused by the oxide layer is, therefore, acceptable. However, the oxide layer yields different mechanical properties as compared to the inner material and will certainly fracture when the specimens are strained. This implies the generation of cracks from the surfaces of the miniaturized specimens to be a likely cause for premature failure as well. Figure 6 provides the evidence for this standpoint. The specimens of 45 and 80 $\mathrm{MPa}$ (fractured) were mechanically polished and the specimens of 60 and $80 \mathrm{MPa}$ (interrupted) were not mechanically polished. As mentioned before, polishing has no significant effect on crack formation. Since the cracks form as intergranular cracks, the edge crack density is expected to be similar and independent of the stress level. The accumulated crack length is generally smaller for the specimens tested at higher stresses, suggesting that for high stresses, propagation of individual cracks is dominant, while at lower stresses, initiation of a network of intergranular cracks seems to be more favored. For a systematic study of the crack length density under various loading conditions, the number of tests is obviously not sufficient.

The miniaturized specimens tested here possess a high surface-volume ratio so that cracks forming at the surface - especially if they propagate as intergranular cracks along grains that extend over a considerable fraction of the specimen cross section-may quickly lead to fracture.

Figure 7 shows the creep strain rate plotted versus true strain from the DIC analysis for the miniaturized specimens tested at $850{ }^{\circ} \mathrm{C}$ together with the results at the same test conditions for the conventional specimens for two initial stress levels (66 and $80 \mathrm{MPa}$, respectively). While the secondary/minimum creep strain rates are similar to the steady-state ones observed for the bulk specimens, the overall shapes of the creep curves are quite different. As already mentioned, the fracture strain is considerably smaller for the miniaturized specimens and there is an early onset of tertiary creep, but as shown for the red and green creep curves, there is a clear tendency toward larger strains to failure when increasing the volume of the sample in the gauge length even if only one dimension of the gauge cross section has been doubled (green curve). We therefore believe that in the miniaturized creep specimens (i) there is currently still a surface effect which leads to premature failure and (ii) the current sample size is too small to mimic the behavior of the conventional samples. Thus, in future, we will continue tests with larger sample geometries in cross section to find the minimum sample size leading to comparable creep behavior. The DIC analysis for the very early stage of creep is met with uncertainties from specimen adjustment (setting) processes that require manual correction and disposal of some of the images. The analysis of the primary creep regime has, therefore, some difficulties and may not be possible for all of the tests. In the tertiary stage, localization effects were eliminated in the DIC analysis by selecting areas at the end of the gauge length for the strain measurement in an "extensometer-like" fashion so that both, the 

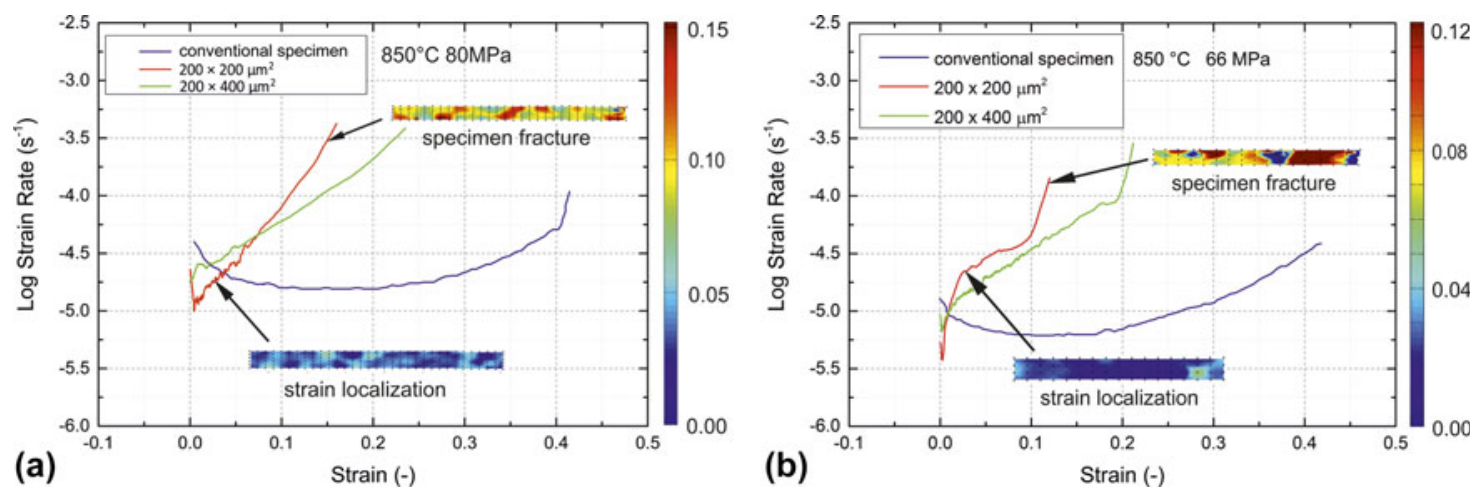

FIG. 7. Creep strain rate versus strain curves for conventional and miniaturized specimens at $850{ }^{\circ} \mathrm{C}$ and (a) $80 \mathrm{MPa}$ (b) $66 \mathrm{MPa}$ together with the strain distribution for $200 \times 200 \mu \mathrm{m}^{2}$ specimen from the DIC analysis at the onset of tertiary creep and before fracture, respectively. (color online)

inhomogeneous, local strain distributions within the gauge area as well as the global strain along the gauge length are available. Figure 7 contains insets of the local strain distribution along the curve with the global strain rate versus the strain plot.

The first indication that the size of the miniaturized specimens is relevant for the fracture behavior is given by test results from miniaturized specimens with a rectangular cross section of $200 \times 400 \mu \mathrm{m}^{2}$, hence doubling the width of the samples while keeping the other dimension constant, tested at $850{ }^{\circ} \mathrm{C}$ and $80 \mathrm{MPa}$. Table I summarizes the creep results for the different specimen geometries under nominal identical stress and temperature. The fracture strain of two specimens with the double thickness, one polished and one in the EDM condition (unpolished), reached a value of 0.26 , considerably above that of the smaller, quadratic specimens. Also no significant effect on the creep life time was observed from polishing.

Our observations of a specimen thickness effect are in line with the early work of Gibbons on Nimonic- $90,{ }^{22}$ where a thickness debit for specimens of $0.15-1.7 \mathrm{~mm}$ thickness and similar grain size were observed. Several authors observed a similar effect for directionally solidified $^{23}$ as well as single crystalline ${ }^{21,23}$ Ni-base superalloys (PWA1484, M247LC SX), where oxidation was made responsible for a reduction in creep life and an increase of minimum creep strain rate with decreasing the thickness of the specimens. However, the oxidation mechanism in the Ni-base superalloys leads to the deterioration of the $\gamma^{\prime}$-phase, ${ }^{20,21}$ which is not present in Nimonic-75. Seetharaman and $\mathrm{Cetel}^{23}$ additionally mention the differences in deformation constraint and plastic anisotropy between the thick and thin sections and obtain a limit for the thickness debit which is around $4 \mathrm{~mm}$. Mälzer et al. ${ }^{6}$ (LEK94) use specimens with a $2 \times 2 \mathrm{~mm}^{2}$ gauge section and obtain results in reasonable agreement with results from standard specimens, whereas Wen et al. ${ }^{24}$ (DD6) observe results similar to conventional specimens at a thickness of $1.2 \mathrm{~mm}$. Gibbons $^{22}$ obtains creep cavitation as the responsible failure mechanism for Nimonic-90 and states $1 \mathrm{~mm}$ thickness as the limit for the decrease in creep performance. In conclusion, we have to note that the current sample geometry falls clearly into the regime where superimposed surface effects on the creep behavior have to be expected.

\section{CONCLUSION AND OUTLOOK}

In this study, we introduced a customized setup to test the tensile creep properties of the miniaturized specimens (with gauge dimensions of $0.2 \times 0.2 \times 1 \mathrm{~mm}^{3}$ ). The creep tests with Nimonic-75 as the reference material at temperatures between $850{ }^{\circ} \mathrm{C}$ and $1000{ }^{\circ} \mathrm{C}$ and within a stress range from 10 to $150 \mathrm{MPa}$ verified the general feasibility of this test method and revealed the specific creep properties of the miniaturized specimens. The following conclusions were obtained:

(1) With the customized setup presented in this article, tensile creep tests can be performed at temperatures up to $1000{ }^{\circ} \mathrm{C}$ under constant load conditions of stresses from 10 to $150 \mathrm{MPa}$. The stress dependence of the minimum creep rates of the miniaturized specimens is in good agreement with steady-state creep strain rates for the conventional specimens, despite the fact that the gauge section contains only a few grains. Further, a comparable value for the creep activation energy was also obtained.

(2) The fracture strain for the miniaturized specimens is significantly lower compared to the conventional specimens. The miniaturized specimens have a shorter secondary creep stage and an earlier onset of tertiary creep compared to the conventional specimens. This is possibly due to the increasing stress under constant load testing conditions and strain localization, and it would be particularly pronounced for materials with even larger stress exponents. ${ }^{9,10}$

(3) With increased specimen size, the observed fracture strain seems to approach that of conventional specimens. Further investigations have to provide if there is a limit for the minimum size of the creep specimens with 
a cross-sectional area somewhere between the $0.2 \times$ $0.2 \ldots 0.4 \mathrm{~mm}^{2}$ of the present study and the $2 \times 3 \mathrm{~mm}^{2}$ of Ref. 5, where a reasonable agreement with standardsized specimens had been stated.

(4) In contrast to the influence of the constant load mode, the oxidation processes seem to be of minor relevance for creep deformation but may enhance crack initiation on the surface with increasing strain.

\section{ACKNOWLEDGMENTS}

This research was financially supported by the Helmholtz Association of German Research Centers under the framework of the Helmholtz Research School on "Integrated Materials Development for Novel High Temperature Alloys", Grant No. VH-KO-610.

\section{REFERENCES}

1. D.S. Gianola and C. Eberl: Micro-and nanoscale tensile testing of materials. JOM 61(3), 24 (2009).

2. K.J. Hemker and W.N. Sharpe: Microscale characterization of mechanical properties. Annu. Rev. Mater. Res. 37(1), 93 (2007).

3. M. Zupan, M.J. Hayden, C.J. Boehlert, and K.J. Hemker: Development of high-temperature microsample testing. Exp. Mech. 41(3), 242 (2001).

4. N.J. Karanjgaokar, C-S. Oh, and I. Chasiotis: Microscale experiments at elevated temperatures evaluated with digital image correlation. Exp. Mech. 51(4), 609 (2011).

5. D. Peter, F. Otto, T. Depka, P. Nörtershäuser, and G. Eggeler: High temperature test rig for inert atmosphere miniature specimen creep testing. Materialwiss. Werkstofftech. 42(6), 493 (2011).

6. G. Mälzer, R.W. Hayes, T. Mack, and G. Eggeler: Miniature specimen assessment of creep of the single-crystal superalloy LEK 94 in the $1000{ }^{\circ} \mathrm{C}$ temperature range. Metall. Mater. Trans. A 38(2), 314 (2007).

7. D. Leisen, R. Rusanov, F. Rohlfing, T. Fuchs, C. Eberl, H. RieschOppermann, and O. Kraft: Mechanical characterization between room temperature and $1000{ }^{\circ} \mathrm{C}$ of $\mathrm{SiC}$ free-standing thin films by a novel high-temperature micro-tensile setup. Rev. Sci. Instrum. 86(5), 055104 (2015).

8. B.V. Grossmann, H. Biermann, and H. Mughrabi: Measurement of service-induced internal elastic strains in a single-crystal nickelbased turbine blade with convergent-beam electron diffraction. Philos. Mag. A 80(8), 1743 (2000).

9. J. Albiez, I. Sprenger, C. Seemüller, D. Weygand, M. Heilmaier, and T. Böhlke: Physically motivated model for creep of directionally solidified eutectics evaluated for the intermetallic NiAl-9Mo. Acta Mater. 110, 377 (2016).

10. M. Heilmaier: Modellkompatible Beschreibung des Kriech-und Zeitstandverhaltens oxiddispersionsgehärteter Nickelbasissuperle- gierungen (model-based description of the creep deformation and fracture behavior of oxide-dispersion strengthened nickel-base superalloys). Ph.D. thesis, VDI-Verlag, Düsseldorf, 1993.

11. M. Heilmaier and B. Reppich: Creep lifetime prediction of oxidedispersion-strengthened nickel-base superalloys: A micromechanically based approach. Metall. Mater. Trans. A 27(12), 3861 (1996).

12. M. Nganbe and M. Heilmaier: High temperature strength and failure of the Ni-base superalloy PM 3030. Int. J. Plast. 25, 822 (2009).

13. C. Eberl, R. Thompson, D.S. Gianola, and S. Bundschuh: Digital image correlation and tracking (Matlab Central File ID:12413, The Mathworks, Inc., Natick, MA, 2006).

14. C. Eberl, D.S. Gianola, and K.J. Hemker: Mechanical characterization of coatings using microbeam bending and digital image correlation techniques. Exp. Mech. 50(1), 85 (2010).

15. T.C. Chu, W.F. Ranson, M.A. Sutton, and W.H. Peter: Applications of digital-image-correlation techniques to experimental mechanics. Exp. Mech. 25(3), 232 (1985).

16. D. Lecompte, A. Smits, S. Bossuyt, H. Sol, J. Vantomme, D. Van Hemelrijck, and A.M. Habraken: Quality assessment of speckle patterns for digital image correlation. Opt. Lasers Eng. 44(11), 1132 (2006).

17. B. Pan, H. Xie, Z. Wang, K. Qian, and Z. Wang: Study on subset size selection in digital image correlation for speckle patterns. Opt. Express 16(10), 7037 (2008).

18. M.A. Sutton, J.H. Yan, V. Tiwari, H.W. Schreier, and J.J. Orteu: The effect of out-of-plane motion on 2D and 3D digital image correlation measurements. Opt. Lasers Eng. 46(10), 746 (2008).

19. H.J. Frost and M.F. Ashby: Deformation Mechanism Maps (Pergamon Press, Oxford, 1982).

20. F. Krieg, M. Mosbacher, M. Fried, E. Affeldt, and U. Glatzel: Creep and oxidation behaviour of coated and uncoated thin walled single crystal samples of the alloy PWA1484. In Superalloys 2016: Proc. 13th Inter. Symp. Superalloys, M. Hardy, E. Huron, U. Glatzel, B. Griffin, B. Lewis, C. Rae, V. Seetharaman, and S. Tin, eds. (TMS, 2016); p. 773.

21. M. Bensch, E. Fleischmann, C.H. Konrad, M. Fried, C.M.F. Rae, and U. Glatzel: Secondary creep of thin-walled specimens affected by oxidation. In Superalloys 2012: Proc. 12th Inter. Symp. Superalloys, E.S. Huron, R.C. Reed, M.C. Hardy, M.J. Mills, R.E. Montero, P.D. Portella, and J. Telesman, eds. (TMS, 2012); p. 387.

22. T.B. Gibbons: Creep properties of Nimonic 90 in thin section. Met. Technol. 8(1), 472 (1981).

23. V. Seetharaman and A.D. Cetel: Thickness debit in creep properties of PWA 1484. In Superalloys 2004: Proc. 10th Inter. Symp. Superalloys, K.A. Green, T.M. Pollock, and H. Harada, eds. (TMS, 2004); p. 207.

24. Z.X. Wen, H.Q. Pei, D.F. Li, Z.F. Yue, and J.Y. Gao: Thickness influence on the creep response of DD6 Ni-based single-crystal superalloy. High Temp. Mater. Processes 35(9), 871 (2016). 


\section{AUTHOR QUERY - jmr.2017.414}

1 Please provide the manufacturer details (company name, city/state if produced in the US or city/country name if produced outside US) for 'Nikon Eclipse LV150N; Kanthal A1'.

2 Please provide the publisher location for references '20, 21, and 23'.

\section{EDITOR QUERY - jmr.2017.414}

There are no editor queries for this article. 